\title{
Human Herpesvirus 8-Associated Solid Lymphomas that Occur in AIDS Patients Take Anaplastic Large Cell Morphology
}

Harutaka Katano, D.D.S., Tetsuji Suda, M.Sc., Yasuyuki Morishita, Katsuya Yamamoto, M.D.,

Yoshihiko Hoshino, M.D., Koichiro Nakamura, M.D., Natsuo Tachikawa, M.D., Tetsutaro Sata, M.D., Hiroyuki Hamaguchi, M.D., Aikichi Iwamoto, M.D., Shigeo Mori, M.D.

Department of Pathology, Institute of Medical Science, University of Tokyo (HK, TSu, YM, SM); Department of Hematology, Musashino Red Cross Hospital (KY, HH); Department of Infectious Diseases, Institute of Medical Science (KN), and Department of Dermatology, Faculty of Medicine (YH, AI), University of Tokyo; Department of Infectious Diseases, International Medical Center of Japan (NT); Department of Pathology (HK, TSa) and Laboratory of Pathology, AIDS Research Center (TSa), National Institute of Infectious Diseases, Tokyo; and Department of Molecular and Cell Genetics, School of Life Science, Faculty of Medicine, Tottori University (HK), Tottori, Japan.

Human herpesvirus type 8 (HHV-8; Kaposi's sarcoma-associated herpesvirus) is a recently isolated human herpesvirus frequently identified in Kaposi's sarcoma, primary effusion lymphoma, and multicentric Castleman's disease. Here we report three cases of HHV-8-bearing solid lymphomas that occurred in AIDS patients (Cases 1-3). All three patients were homosexual men presenting extranodal masses in the lungs (Case 1) or skin (Cases 2 and 3), together with the presence of Kaposi's sarcoma (Case 1), primary effusion lymphoma (Case 2), or multicentric Castleman's disease (Case 3). These solid lymphomas exhibited anaplastic large cell morphology and expressed CD30, corresponding to the recent diagnostic criteria of anaplastic large cell lymphoma (ALCL). The chromosomal translocation $t(2 ; 5)$-associated chimeric protein $\mathrm{p} 80^{\mathrm{NPM} / \mathrm{ALK}}$ was not observed in any of these cases. HHV-8 was detected in all of these cases by polymerase chain reaction, immunohistochemistry of HHV-8-encoded ORF73 protein, and in situ hybridization of T1.1. Epstein-Barr virus was detected only in Cases 2 and 3 by in situ hybridization. It is interesting that inoculation of a cell line obtained from a primary effusion lymphoma cell in Case 2 to severe combined immunodeficiency mice produced HHV-8positive and Epstein-Barr virus-negative tumors in

Copyright () 2000 by The United States and Canadian Academy of Pathology, Inc.

VOL. 13, NO. 1, P. 77, 2000 Printed in the U.S.A.

Date of acceptance: July 28, 1999.

Address reprint requests to: Dr. Harutaka Katano, Department of Pathology, National Institute of Infectious Diseases, 1-23-1 Toyama, Shinjukuku, Tokyo 162-8640, Japan; e-mail: katano@nih.go.jp; fax: 81-3-52851189. inoculated sites. These tumor cells exhibited phenotypes of ALCL that were identical to the subcutaneous tumor cells of this particular patient. These findings clearly show that HHV-8 can associate with solid lymphomas and that it can take anaplastic large cell morphology. Those lymphomas should be distinguished from the classical ALCL as were defined by the revised European-American classification of lymphoid neoplasms even though morphology and a part of immunophenotype mimic that of classical ALCL.

KEY WORDS: Anaplastic large cell lymphoma, Human herpesvirus-8, Kaposi's sarcoma-associated herpesvirus, Multicentric Castleman's disease, Primary effusion lymphoma.

Mod Pathol 2000;13(1):77-85

Most of the acquired immunodeficiency syndrome (AIDS)-associated lymphomas take the morphology of diffuse large cell lymphoma, immunoblastic lymphoma, or Burkitt's lymphoma, whereas several cases in which lymphoma cells took anaplastic large cell morphology have been reported (1). Approximately 30 reported cases have used the term "AIDS-associated anaplastic large cell lymphomas (AIDS-ALCLs)" under the somewhat ambiguous definition of ALCL (2-6). Such AIDS-ALCLs were reported to occur much more frequently in extranodal organs, including the skin, lung, liver, bone marrow, and gastrointestinal tract (2-6). Their clinical courses were less favorable than the other AIDS-associated lymphomas. Indeed, the immunophenotype of these reported AIDS-ALCLs was confusing: Chadburn et al. (2) reported 10 cases of 
AIDS-ALCLs in which were included 4 T-cell, 1 B-cell, and 3 null-cell type lymphomas, whereas many of the cases reported by Nosari et al. (3) and Tirelli et al. (4) were the B-cell lymphomas. DePond et al. (6) reported two cases of human herpesvirus-8 (HHV-8)-associated solid lymphomas of null-cell type. It is interesting that DePond et al.'s cases occurred first as solid lymphomas and later developed lymphomatous effusion. The Epstein-Barr virus (EBV) genome was detected in 30 to $50 \%$ of those AIDS-ALCLs cases, whereas the detailed pathogenesis of those AIDS-ALCLs has remained unclarified (2-6).

ALCL is a subtype of non-Hodgkin's lymphoma (NHL) characterized by its peculiar, large anaplastic morphology and the expression of $\operatorname{CD} 30(7,8)$. ALCL is classified as a T-/null-cell type lymphoma in the revised European-American classification of lymphoid neoplasm (7). There are some B-cell lymphomas that exhibit anaplastic large cell morphology, however, and although they were excluded from ALCL under this classification, they have been included in ALCL on other classifications, such as the updated Kiel classification (9), leaving some confusion or discrepancy in the definition of ALCL. The recent identification of chromosomal translocation $\mathrm{t}(2 ; 5)$-associated chimeric protein $\mathrm{p} 80^{\mathrm{NPM} / \mathrm{ALK}}$ as the pathogenic molecule for approximately half of the ALCLs gave a new impact to the classification of ALCL (8, 10-13). Thus, ALCLs are currently classified first into $\mathrm{p} 80^{\mathrm{NPM} / \mathrm{ALK}}$-positive and -negative cases $(8,12)$. The $\mathrm{p} 80^{\mathrm{NPM} / \mathrm{ALK}}$-positive ALCLs seem to be a single disease, whereas the $\mathrm{p} 80^{\mathrm{NPM} / \mathrm{ALK}}$-negative cases are composed of heterogeneous diseases in terms of their lineage and probably also in their pathogenesis (8). The B-cell ALCLs, if this category is admitted, are included in the $\mathrm{p} 80^{\mathrm{NPM} / \mathrm{ALK}}$-negative ALCL (12). Meanwhile, under the strictest definition, the term ALCL is devoted to the $\mathrm{p} 80^{\mathrm{NPM} / \mathrm{ALK}}$-positive cases and cases identical in phenotype to those $\mathrm{p} 80^{\mathrm{NPM} / \mathrm{ALK}}$-positive cases, and under this definition, B-cell lymphomas that take anaplastic large cell morphology are excluded from ALCL (8).

Until now, three cases of solid AIDS-ALCLs were shown to have association with HHV-8 (Kaposi's sarcoma-associated herpesvirus) $(5,6)$. Two of them occurred as secondary effusion lymphomas; the association of AIDS-ALCL with HHV-8 in those cases was suggested by polymerase chain reaction (PCR) study (6). The third case occurred as a solid lymphoma without effusion (5). HHV-8 is a recently identified human herpesvirus that is frequently identified in Kaposi's sarcoma, primary effusion lymphoma (PEL), and multicentric Castleman's disease (MCD) (14-17). PEL is a subtype of NHL in which neoplastic cells proliferate in the pleural, pericardial, or peritoneal effusion without forming a tumor mass $(15,16)$. Whereas a large portion of the AIDS-associated PELs bear HHV-8, there are only a small number of AIDS-associated solid lymphomas in which HHV-8 was identified in substantial quantities (18). HHV-8 is a DNA virus of $170 \mathrm{kbp}$ (19). Based on the nucleotide sequence, HHV-8 encodes cellular homologues of various oncogenes and cytokines, including bcl-2, cyclin-D, interleukin-6 (IL-6), and G-protein coupled receptor (20). Among these, viral G-protein coupled receptor was reported to induce transformation and tumor formation on NIH3T3 cells (21). In addition, a specific viral gene expressed in PEL cells but not in Kaposi's sarcoma cells, K9, is believed to play a role in lymphomagenesis by HHV-8; however, no direct evidence has been reported (22).

Here we report three cases of HHV-8-associated solid lymphomas with anaplastic large cell morphology. We stress through this study that HHV-8 can associate with solid lymphomas and that such solid lymphomas can take anaplastic large cell morphology. Also, we stress that those cases should be distinguished as a different entity from the classical ALCLs as defined by the REAL classification.

\section{CASE PRESENTATION}

\section{Case 1}

A 59-year-old Japanese homosexual man developed a fever in June 1993. Upon laboratory examination, he was found to carry HIV. He complained of diarrhea and a high fever $\left(39^{\circ} \mathrm{C}\right)$ in October. His $\mathrm{CD} 4$ count was 6 cells/ $\mu$ l. Chest $\mathrm{x}$-ray revealed diffuse nodular shadows in all lobes of the lung. However, bronchial fibroscopy could not identify any pathogenic organisms, such as Pneumocystis carinii, Mycobacterium avium, or fungi. On October 12, a spike fever appeared with an increase of nodular shadows. Kaposi's sarcoma was noted in the oral cavity. Adriamycin, vinblastine, and bleomycin had been administered since October 28 without effect. Cytomegalovirus-related severe diarrhea and ileus developed into a terminal condition. The patient died on November 4, 1993. Autopsy revealed multiple nodular lesions in bilateral lungs. A tentative histopathologic diagnosis of these nodules was ALCL. Kaposi's sarcoma was noted in the stomach and left leg; the presence of PEL could not be confirmed because of purulent ascites and pleural effusion as a result of the perforation of the intestine.

\section{Case 2}

The clinical course of this patient was reported previously $(23,24)$. Briefly, a 45 -year-old Japanese homosexual AIDS patient experienced respiratory distress and was admitted in August 1996. He was 
diagnosed as an HIV carrier with Pneumocystis carinii pneumonia. His CD4 cell count was 8 cells/ $\mu$ l. Pericardial effusion was noted in December 1996, from which typical PEL cells were identified. CHOP chemotherapy decreased the pericardial effusion; however, the patient died in May 1997 as a result of generalized cytomegalovirus infection. Upon autopsy, no pericardial effusion was noted. However, multiple fingertip-sized masses were noted on the chest wall. The tentative diagnosis of these masses with histopathologic survey was ALCL.

\section{Case 3}

A 30-year-old Japanese homosexual man who had a fever, generalized lymphoadenopathy, and hepatosplenomegaly was admitted in December 1997. Laboratory examination revealed anemia, thrombocytopenia, polyclonal hyperglobulinemia, and a high level of IL-6. HIV RNA was detected in the serum. His CD4 cell count was 50 cells/ $\mu$ l. A cervical lymph node biopsy revealed the typical morphology of MCD. Erythematous nodular lesions of fingertip size were noted in the cervical region. A biopsy revealed these lesions to be filled by large anaplastic lymphoid cells. Chemotherapy using vinblastine and cyclophosphamide reduced these skin lesions. The patient died in July 1998 because of MCD and hemorrhage. No evidence of Kaposi's sarcoma or PELs was detected.

\section{MATERIALS AND METHODS}

\section{Histopathology and Immunohistochemistry}

Formalin-fixed tumor specimens obtained from these patients were embedded in paraffin, sectioned, and stained with hematoxylin and eosin. Immunohistochemistry was performed with mouse monoclonal antibodies including CD3 (A0452; DAKO, Glostrup, Denmark), CD20 (L26, DAKO), CD30 (BerH2, DAKO), CD43 (DF-T1, DAKO), CD45 (LCA, DAKO), CD45RO (UCHL-1, DAKO), CD68 (KP-1, DAKO), CD79a (JCB117, DAKO), CD138 (Syndecan-1; Serotec, Oxford, UK), epithelial cell membrane antigen (DAKO), IgG (DAKO), IgA (DAKO), Ig light chain kappa (DAKO), lambda (DAKO), antip80 NPM/ALK rabbit polyclonal antibody (Nichirei Co., Tokyo, Japan), and anti-HHV-8-ORF73 rabbit antiserum (25) as the primary antibodies. For the second and third phase reagents of immunostaining, a biotinylated $\mathrm{F}\left(\mathrm{ab}^{\prime}\right) 2$ fragment of rabbit antimouse immunoglobulin (DAKO)/goat anti-rabbit immunoglobulin (DAKO) and peroxidase-conjugated Streptavidin (DAKO) were used. Details regarding the immunostaining have been described previously (26). The detailed specificity of anti-HHV-8-ORF73 rabbit antiserum was described previously (25). Briefly, this antibody recognized $220-230 \mathrm{kDa}$ latent nuclear antigen in lysate of HHV-8-infected PEL cell lines in Western blot. In immunohistochemistry, almost all HHV-8-infected PEL cells and the spindle cells of Kaposi's sarcoma lesions were stained with this antibody specifically.

\section{In Situ Hybridization}

In situ hybridization (ISH) was performed to detect EBV-encoded small RNA-1 (EBER1) and HHV8-T1.1/ nut-1, which is specifically expressed in the lytic phase of HHV-8 infection (27). As a probe for the EBER1 gene, a digoxigenin (DIG)-labeled 30 base oligonucleotide $5^{\prime}$-aga cac cgt cct cac cac ccg gga ctt gta-3' was used (28), and for HHV-8-T1.1/ nut-1, a DIG-labeled 50 base oligonucleotide, 5'gag cgc tcc cag ctg ccg cac acc act tta gtc caa tgt tct tac act ac-3', was used (27). The DIG Oligonucleotide 3'-Tailing Kit (Boehringer Mannheim, Mannheim, Germany) was used for the labeling of the probe. The details of this method were performed according to the manufacturer's instructions. Briefly, deparaffinized slides were digested with proteinase $\mathrm{K}(10 \mu \mathrm{g} / \mathrm{mL})$ at $37^{\circ} \mathrm{C}$ for $15 \mathrm{~min}$ and rinsed with $4 \%$ paraformaldehyde in $0.1 \mathrm{M}$ phosphate buffer (PB; pH 7.2). The slides were treated with $0.2 \mathrm{M} \mathrm{HCl}$ for $10 \mathrm{~min}$, rinsed with $\mathrm{PB}$, and dehydrated with a graded series of ethanol. Hybridization was performed in $20 \mu \mathrm{l} /$ slide of hybridization mixture consisting of $30 \%$ formamide, $2 \times$ SSC $(0.15 \mathrm{M} \mathrm{NaCl}, 0.015 \mathrm{~m}$ sodium citrate), $1 \times$ Denhardt's solution $(0.02 \%$ bovine serum albumin fraction V, $0.02 \%$ Ficoll type 400 and $0.02 \%$ polyvinylpyrrolidone), $150 \mu \mathrm{g} / \mathrm{mL}$ single-stranded herring sperm DNA, $10 \%$ dextran sulfate, and $10 \mathrm{pmol} / \mathrm{mL}$ of the DIG-labeled oligonucleotide probe. After hybridization for $15 \mathrm{~h}$ at $37^{\circ} \mathrm{C}$, the slides were rinsed at room temperature in $2 \times$ SSC for 10 min twice, $0.5 \times$ SSC for $10 \mathrm{~min}$, and then DIG buffer 1 for 5 min three times. After the slides were blocked with the DIG buffer 2 for $30 \mathrm{~min}$, they were rinsed with DIG buffer 1 for 3 min three times and incubated with $500 \times$ diluted anti-DIG antibody for $30 \mathrm{~min}$ at $37^{\circ} \mathrm{C}$. Detection was performed with nitro blue tetrazolium salt.

\section{Polymerase Chain Reaction}

To determine the presence of HHV-8 DNA in lymphoma tissues, PCR analysis was performed. All of the DNA samples were confirmed to be amplifiable by the use of PCR primers specific for a conserved region of the human $\beta$-actin gene. PCR primers for HHV-8 were synthesized to amplify the $233 \mathrm{bp} \mathrm{KS} 330_{233}$ region of this virus (14). Each PCR reaction used approximately $0.2 \mu \mathrm{g}$ of genomic 
DNA, 100 pmol of each primer (5'-agc cga aag gat tcc acc at- $3^{\prime}$ and $5^{\prime}$-tcc gtg ttg tct acg tcc ag- $3^{\prime}$ ), 2 units of Taq polymerase, $100 \mathrm{~mm}$ of each deoxynucleotide triphosphate, $1.5 \mathrm{~mm}$ Trishydrochloride ( $\mathrm{pH} 9.0)$, and $0.1 \%$ Triton $\mathrm{X}-100$ in a final volume of $50 \mu$ l. PCR amplification was carried out at $95^{\circ} \mathrm{C}$ for $2 \mathrm{~min}$ ( 1 cycle); $95^{\circ} \mathrm{C}$ for $1 \mathrm{~min}, 58^{\circ}$ $\mathrm{C}$ for $1 \mathrm{~min}$, and $72^{\circ} \mathrm{C}$ for $1.5 \mathrm{~min}$ (35 cycles); and $72^{\circ} \mathrm{C}$ for $5 \mathrm{~min}$ (1 cycle). Amplification was performed with a GeneAmp PCR System 9600 (PerkinElmer, Norwalk, CT). PCR products were visualized on $2 \%$ agarose gel containing ethidium bromide.

Inoculation of a PEL Cell Line TY-1 to Severe Combined Immunodeficiency Mice

A PEL cell line TY-1 was established from Case 2 (24). Briefly, lymphoma cells in the pericardial effusion of Case 2 were collected and grown in RPMI1640 supplemented with $20 \%$ fetal bovine serum, $10 \mathrm{ng} / \mathrm{mL}$ insulin (Sigma), $10 \mathrm{ng} / \mathrm{mL}$ transferrin (Sigma), and $10 \%$ supernatant of pericardial effusion. The addition of pericardial effusion was gradually reduced, and eventually the cells could grow without its addition. Single-cell cloning was performed, and the cell line obtained was named TY-1. TY-1 was characterized as a CD30-positive, HHV-8-positive, and EBV-negative lymphoma cell line (24).

TY-1 was injected into the abdominal cavity of 8to 10-week-old C.B. 17 severe combined immunodeficiency (SCID)/SCID mice (SCID mice). $1 \times 10^{7}$ cells were inoculated in each SCID mouse. TY-1 cells injected were not pretreated by tissue plasminogen activator or n-butylate. Animals were euthanized with diethyl ether in accordance with the University of Tokyo guidelines for the care and handling of mice.

\section{RESULTS}

\section{Histopathologic Analysis}

Solid tumors from the three cases were extranodal lymphomas. In Case 1, multiple nodular lesions of up to fingertip size were observed in all lobes of the lungs. In Cases 2 and 3, tumors were observed in the dermis of the chest wall, both measuring approximately $2 \mathrm{~cm}$ in diameter (Figs. 1a-c). These three specimens shared the following histopathologic features: (1) anaplastic large blastic cell morphology with occasional horseshoeshaped/multiple nuclei with two or single prominent nucleoli; (2) much larger in size than the cells found in ordinal large cell lymphomas, with greater cytoplasmic volume; and (3) growing in a cohesive sheet-like pattern. This histology matched the current morphologic criteria for ALCL $(7,9)$.
Immunophenotypic Analysis

Immunohistologic analysis revealed that these three cases were positive for CD30 (Figs. 1d-f) and CD45 but negative for CD3, CD68, CD79a, CD138, IgG, IgA, Ig light chain kappa, and lambda (Table 1). The expression of CD30 was variable. In Case 2, almost all tumor cells expressed CD30, whereas only a small population of cells were stained in Cases 1 and 3. CD20 was positive in Case 3 but not in others. CD43 was positive in Case 2 (partially) and Case 3. Epithelial cell membrane antigen was positive in Case 1 but not in others. These results correspond to the immunophenotype of reported PEL (16), except for the expression of CD20 in one case (8). $\mathrm{P} 80^{\mathrm{NPM} / \mathrm{ALK}}$ was not demonstrated in any of these cases. Concerning clonal identity of solid lymphoma and PEL of Case 2, we could present a Southern blot analysis, which revealed both a cutaneous solid lymphoma and PEL to show the same rearrangement pattern on the immunoglobulin gene (23).

\section{Demonstration of HHV-8 by PCR, ISH, and Immunohistochemistry}

On PCR analysis, bands compatible with HHV-8 genomic sequences were detected in all three cases (Fig. 2). ISH analysis exhibited positive signals for HHV-8-T1.1/nut-1 in all three cases (Figs. 1g-i). The number of signal-positive cells was small, consisting of 1 to $2 \%$ of all of the neoplastic cells, probably because T1.1/nut-1 is the lytic gene and thus is expressed in a limited number of infected cells (27). The nucleus was shown to be the main site of hybridization on signal-positive cells. Immunohistochemistry for HHV-8 ORF73 protein revealed that this antigen was detected in the nucleus of almost all of the tumor cells of Cases 2 (Fig. 3E) and 3 (data not shown). In Case 1, however, obvious positive signals were limited. Because the sample of Case 1 was derived from autopsy, its antigenicity was not well shown on other antigens. These data suggest that the lymphomas studied were infected with HHV-8 and were in latent phase mostly. A few EBER1-positive cells were detected in Cases 2 and 3 , but not in Case 1 (Table 1).

\section{Increase of Plasma Cells in the Bone Marrow}

We incidentally noted an increase of plasma cells in the bone marrow of all of these cases. To confirm this finding, vertebral bone marrow pathology slides obtained at autopsy were studied. Histopathologic findings of the bone marrow were as follows: hypercellular bone marrow (fat/cell ratio was approximately $1 / 2 \sim 1 / 3$ ); no definitive neoplas- 
Case 1

ALCL

HE

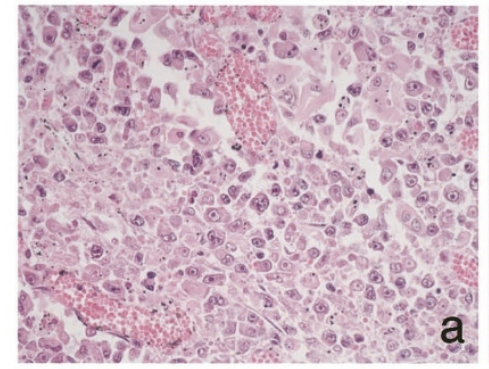

$\mathrm{HHV}-8$

Bone

Marrow

\section{HHV-8- associated complication}

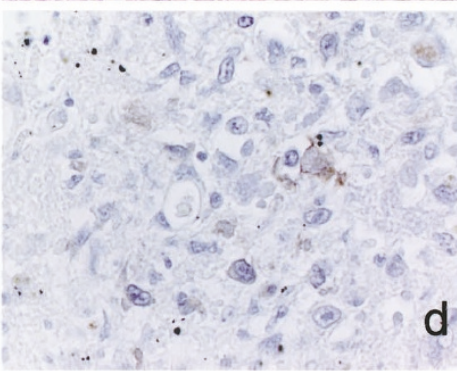

Case 2
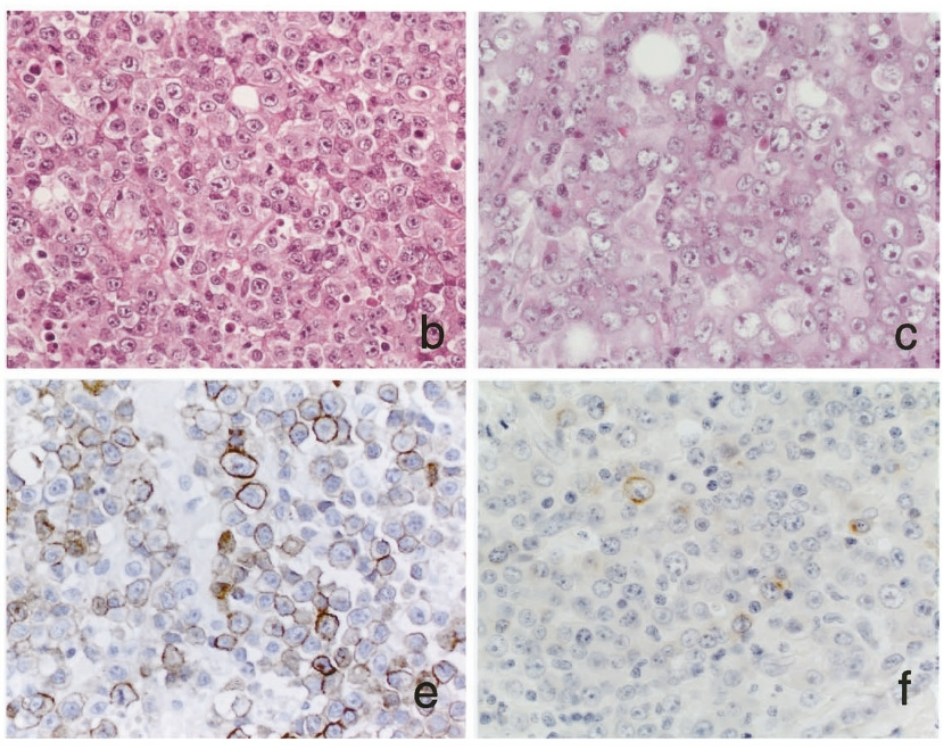

f

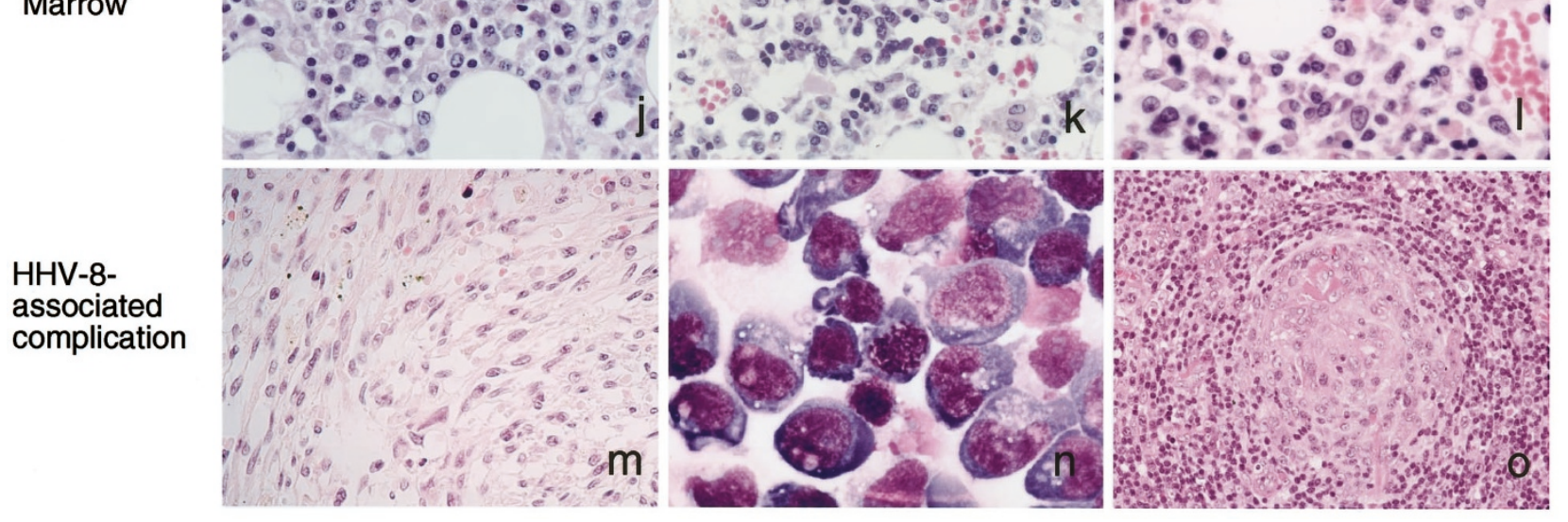

FIGURE 1. Histologic features of acquired immunodeficiency syndrome anaplastic large cell lymphoma. Case 1 (a, d, $\mathbf{g}, \mathbf{j}, \mathbf{m}$ ), Case 2 (b, e, h, $\mathbf{k}, \mathbf{n}$ ), Case 3 (c, f, i, l, o). Hematoxylin and eosin staining of lymphoma (a-c), immunostaining for CD30 (d-f), in situ hybridization for human herpesvirus type $8(\mathbf{g}-\mathbf{i})$, hematoxylin and eosin staining of the bone marrow (j-l). Primary complications are shown in $\mathbf{m}($ Case 1 : Kaposi's sarcoma in the stomach), $\mathbf{n}$ (Case 2: primary effusion lymphoma in the pericardial effusion), and o (Case 3: multicentric Castleman's disease in the cervical lymph node). These three complications were known to be associated with human herpesvirus type 8 .

tic cell infiltration; increase of plasma cells (22 cells per high power view in Case 1, 32 cells in Case 2, and 25 cells in Case 3, composing $11 \%, 16 \%$, and $12 \%$ of the nucleated cells, respectively. Normally, the plasma cell count is less than $3 \%$ of the nucleated cells using the direct count method). Occasionally, plasma cells formed some nests in the stroma of the bone marrow. 
TABLE 1. Pathologic Findings of Cases 1-3

\begin{tabular}{|c|c|c|c|}
\hline & Case 1 & Case 2 & Case 3 \\
\hline Age & 59 & 45 & 30 \\
\hline Sex & Male & Male & Male \\
\hline HIV status & + & + & + \\
\hline CD4 (cells/ml) & 6 & 8 & 50 \\
\hline \multicolumn{4}{|l|}{ ALCL } \\
\hline Site & Lung & Skin & Skin \\
\hline CD3 & - & - & - \\
\hline CD20 & - & - & + \\
\hline CD30 & + & + & + \\
\hline CD43 & - & + (partial) & + \\
\hline CD45 & + & + & + \\
\hline CD45RO & + & - & - \\
\hline CD68 & - & - & - \\
\hline CD79a & - & - & - \\
\hline CD138 & - & - & - \\
\hline EMA & $+($ partial $)$ & - & - \\
\hline IgG & - & - & - \\
\hline $\operatorname{Ig} A$ & - & - & - \\
\hline Ig kappa & - & - & - \\
\hline Ig lambda & - & - & - \\
\hline $\mathrm{p} 80^{\mathrm{NPM} / \mathrm{ALK}}$ & - & - & - \\
\hline EBER1 (ISH) & - & + & + \\
\hline HHV-8 (ISH) & + & + & + \\
\hline $\begin{array}{r}\text { HHV-8-associated } \\
\text { complications }\end{array}$ & $\begin{array}{l}\text { Kaposi's sarcoma } \\
\text { (oral, stomach) }\end{array}$ & $\begin{array}{l}\text { Primary effusion } \\
\text { lymphoma } \\
\text { (pericardial } \\
\text { effusion) }\end{array}$ & $\begin{array}{l}\text { Multicenteric } \\
\text { Castleman's } \\
\text { disease } \\
\text { (general } \\
\text { lymph node) }\end{array}$ \\
\hline $\begin{array}{l}\text { Other } \\
\text { complications }\end{array}$ & $\begin{array}{l}\text { Generalized CMV } \\
\text { infection, HIV } \\
\text { encephalopathy }\end{array}$ & $\begin{array}{l}\text { Generalized CMV } \\
\text { infection, } P \text {. } \\
\text { carinii } \\
\text { pneumonia, } \\
\text { diffuse alveolar } \\
\text { damage }\end{array}$ & - \\
\hline
\end{tabular}

ALCL, anaplastic large cell lymphoma; EMA, epithelial cell membrane antigen; ISH, in situ hybridization; HHV-8, human herpes virus type 8; -, negative; +, positive; CMV, cytomegalovirus.

\section{Tumor Formation in SCID Mice by PEL Cell Line Inoculation}

To determine whether a cell line established from the PEL in Case 2 could form a tumor, we inoculated $1 \times 10^{7} \mathrm{TY}-1$ cells into the abdominal cavity of SCID mice. In 4 weeks, solid tumors of up to $1 \mathrm{~cm}$ in diameter were formed in the mesentery together with marked ascites (Fig. 3A). The neoplastic cells in the solid tumor took the anaplastic large cell morphology, proliferating in a sheet-like growth pattern (Fig. 3B). Also, ascites contained numerous large immunoblastic cells corresponding to TY-1 (24). An immunohistologic study revealed that the lymphoma cells from ascitic fluid and solid tumors shared identical immunophenotypes, such as being positive for CD30 and negative for CD3 and CD20. In addition, HHV-8 was detected in these lymphoma nodules by ISH (Fig. 3C), immunohistochemistry of HHV-8 ORF73 (Fig. 3D), and PCR (data not shown), whereas EBV was not detected by ISH or PCR (data not shown).

\section{DISCUSSION}

We described in this study three cases of AIDSassociated solid lymphomas carrying HHV-8/Kapo- si's sarcoma-associated herpesvirus and exhibiting anaplastic large cell morphology. These findings clearly show that HHV-8 can associate with both solid lymphomas and effusion lymphomas. This study also showed that the HHV-8-associated solid lymphoma can take anaplastic large cell morphology that is hard to distinguish from classical ALCLs. Peculiarly, all of the HHV-8-associated solid lymphomas occurred in extranodal sites. Of these patients, Case 2 had an overlapping of typical PEL and Case 3 had an HHV-8-positive Castleman's tumor, but the presence of PEL could not be confirmed in Cases 1 and 3. Kaposi's sarcoma was found only in Case 1. In two cases, the solid lymphomas represented null-cell immunophenotype and the other case expressed B-cell markers; molecular analysis for the confirmation of their cell lineages was not performed.

There have been approximately 30 cases of AIDSALCL reported (2-6). In those reports, the term "ALCL" was used in a broad sense, based mostly on morphology. There is a great deal of debate regarding the diagnostic criteria of ALCL $(6-9,29,30)$. Our view is that all possible efforts should be made to define each lymphoma subtype so that each subtype reflects a single disease entity. In this sense, ALCLs that express the $\mathrm{p} 80^{\mathrm{NPM} / \mathrm{ALK}}$ chimeric protein constitute a single disease entity, whereas the remaining ALCLs represent various entities. Thus, cases that share identical pathogenetic mechanisms should be excluded from this heterogeneous group. Because it seems that the pathogenesis of these three cases is virtually identical in terms of their association with HHV-8, they should be separated from the category of ALCL. DePond et al. (6)

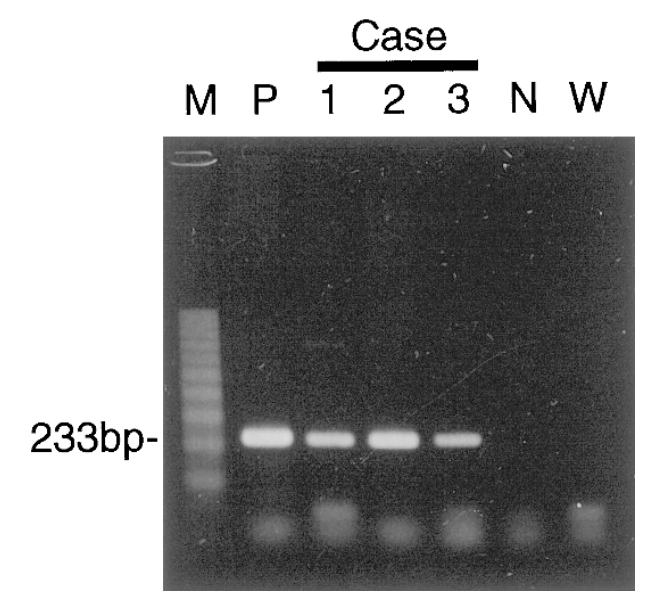

FIGURE 2. Demonstration of human herpesvirus type 8 (HHV-8) sequences with polymerase chain reaction. The $\mathrm{KS}_{3} 30_{233}$ region of HHV-8 was amplified by polymerase chain reaction. M, molecular weight marker (100 bp ladder marker); P, BCBL-1 cell line (HHV-8-positive primary effusion lymphoma cell line, positive control); 1-3, DNA extracted from lymphomas of Cases 1-3; N: Raji cell line (Epstein-Barr virus positive, HHV-8 cell line established from Burkitt's lymphoma, negative control); W, no DNA. All three cases were positive for HHV-8. 

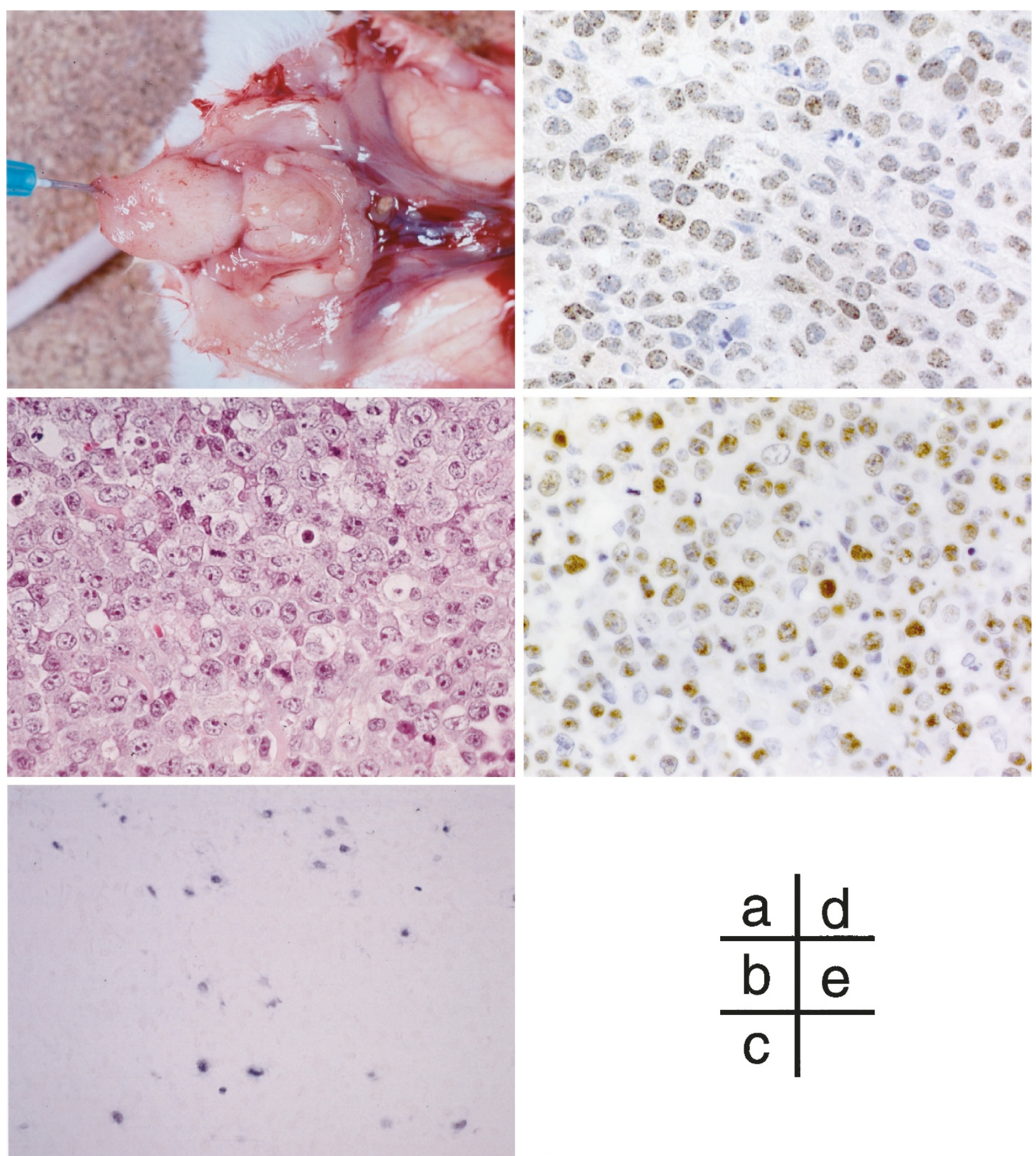

FIGURE 3. Inoculation of a primary effusion lymphoma cell line to severe combined immunodeficiency (SCID) mice. A, tumor formation in a SCID mouse injected with TY-1. B, hematoxylin and eosin staining of tumor of A. Histologic feature of this neoplasm resembles anaplastic large cell lymphoma. C, these tumor cells were positive for human herpesvirus type 8 (HHV-8) by in situ hybridization. D, E, immunohistochemistry of HHV8 -encoded ORF73 protein. D, tumor of a SCID mouse. Dot-like positive signals are found in the nucleus of almost all cells. E, original lymphoma of Case 2. Almost all cells are positive for HHV-8 ORF73.

suggested the association of HHV-8 infection with solid lymphomas. Indeed, in their cases, the effusion lymphomas appeared later, whereas the demonstration of HHV-8 genome remained in PCR level in this study and we could demonstrate the localization of HHV-8 genome and protein definitely. Thus, we believe that these cases constitute the category HHV-8-associated lymphoma, as has been proposed by DePond et al. (6). In this sense, the HHV-8-associated lymphoma can take two forms: effusion lymphoma type and solid lymphoma type. Of course, it is evident from the present study that these two types can appear independently, as in Cases 1 and 3, or simultaneously, as in Case 2. HHV-8-associated lymphoma should be distinguished from the classical ALCLs as 
defined by the REAL classification by the negative expression of $\mathrm{p} 80^{\mathrm{NPM} / \mathrm{ALK}}$ kinase, their B-/null-cell phenotype, and the presence of viral antigens. Actually, in the REAL classification, ALCL belonged to T-/null-cell lymphomas, whereas the present HHV8-associated lymphoma exhibited the null- or B-cell phenotype. Also, we believe that the previously reported AIDS-ALCLs must be reevaluated to take into consideration the presence of HHV-8 infection. So far, the first report of HHV-8-associated lymphoma seems to have been presented by Cesarman et al. (15), in which a solid lymphoma occurred in the submandibular gland and PEL was found in the pleural effusion 5 months later. It might also be important to study the $\mathrm{p} 80^{\mathrm{NPM} / \mathrm{ALK}}$-negative ALCLs to determine whether part of them is related to HHV-8.

EBV was detected in Cases 2 and 3, but we do not think that EBV was an important factor in the progression of these lymphomas because the TY-1 cell line established from a lymphoma in Case 2 was EBV negative, and the solid tumors that occurred in SCID mice that were injected with TY-1 were also negative for EBV.

On the basis of the findings in Case 2 and the experimental inoculation of a PEL cell line into SCID mice, it is highly probable that the lymphoma cells took the form of the effusion lymphoma and the solid lymphomas originated from identical clones. How then, can identical tumor cells take two different forms? So far, we have no speculations that may help answer this question.

It is interesting that the reported PELs were of Bor null-cell immunophenotypes, whereas genetic analysis revealed B-cell genicity in most of the cases. This allows us to speculate that the present two null-cell-type solid lymphomas (Cases 1 and 2) may be of B-cell lineage. Expression of CD30 may be one of the common features in our three cases. CD30 expression is a hallmark of ALCL. Most of the true (classical) ALCLs were shown to express CD30. As shown in this study, the level of expression is variable in HHV-8-associated lymphoma, but they exhibit anaplastic large cell morphology. In addition, two cases of HHV-8-associated lymphoma reported by DePond et al. (6) did not express CD30. Thus, the expression of CD30 seems variable in HHV-8-associated lymphomas.

Finally, the increase of bone marrow plasma cells in these cases might be worth noting. The association of HHV-8 infection to an increase in serum IL-6 was recently confirmed (31). It is also known that PEL cells contain far more HHV-8 copies compared with HHV-8-infected Kaposi's sarcoma cells (15). Thus, it seems possible that those HHV-8-infected solid lymphomas also express this lymphokine, permitting bone marrow plasma cells to proliferate.
Further investigation will be needed to support this speculation.

Acknowledgments: The authors thank Dr. Tomo Wakabayashi, Department of Pathology, Tokyo Senbai Hospital; Dr. Mami Shiota, Department of Pathology, Ms. Mieko Goto, Department of Infectious Diseases, Dr. Atsuko Masunaga, Mr. Haruo Onoda, and Ms. Maki Monna, Department of Laboratory Medicine, Institute of Medical Science, University of Tokyo; and Dr. Takeshi Kurata, Department of Pathology, National Institute of Infectious Diseases, for helpful discussion of the manuscript. The authors also thank Dr. Brian Herndier, Department of Pathology, University of California at San Francisco, for providing an HHV-8-infected cell line, BCBL-1. This study was supported by grants-in-aid for scientific research from the Japanese Ministry of Education, Science and Culture, Tokyo, Japan.

\section{REFERENCES}

1. Herndier BG, Kaplan LD, McGrath MS. Pathogenesis of AIDS lymphomas. AIDS 1994;8:1025-49.

2. Chadburn A, Cesarman E, Jagirdar J, Subar M, Mir RN, Knowles DM. CD30 (Ki-1) positive anaplastic large cell lymphomas in individuals infected with the human immunodeficiency virus. Cancer 1993;72:3078-90.

3. Nosari A, Cantoni S, Oreste P, Schiantarelli C, Landonio G, Alexiadis S, et al. Anaplastic large cell (CD30/Ki-1+) lymphoma in HIV+ patients: clinical and pathological findings in a group of ten patients. Br J Haematol 1996;95:508-12.

4. Tirelli U, Vaccher E, Zagonel V, Talamini R, Bernardi D, Tavio M, et al. CD30 (Ki-1)-positive anaplastic large-cell lymphomas in 13 patients with and 27 patients without human immunodeficiency virus infection: the first comparative clinicopathologic study from a single institution that also includes 80 patients with other human immunodeficiency virus-related systemic lymphomas. J Clin Oncol 1995; 13:373-80.

5. Buske C, Hannig H, Hiddemann W, Bodemer W. Human herpesvirus-8 (HHV-8) DNA associated with anaplastic large cell lymphoma of the B-cell type in an HIV-1-positive patient. Int J Cancer 1997;73:303-4.

6. DePond W, Said JW, Tasaka T, de Vos S, Kahn D, Cesarman E, et al. Kaposi's sarcoma-associated herpesvirus and human herpesvirus 8 (KSHV/HHV8)-associated lymphoma of the bowel: report of two cases in HIV-positive men with secondary effusion lymphomas. Am J Surg Pathol 1997;21: $719-24$

7. Harris NL, Jaffe ES, Stein H, Banks PM, Chan JK, Cleary ML, et al. A revised European-American classification of lymphoid neoplasms: a proposal from the International Lymphoma Study Group. Blood 1994;84:1361-92.

8. Nakamura S, Shiota M, Nakagawa A, Yatabe Y, Kojima M, Motoori T, et al. Anaplastic large cell lymphoma: a distinct molecular pathologic entity-a reappraisal with special reference to p80 ${ }^{\text {(NPM/ALK) }}$ expression. Am J Surg Pathol 1997;21: $1420-32$.

9. Lennert K, Feller AC. Histopathology of non-Hodgkin's lymphomas (based on the updated Kiel classification). Berlin: Springer-Verlag; 1992.

10. Morris SW, Kirstein MN, Valentine MB, Dittmer KG, Shapiro DN, Saltman DL, et al. Fusion of a kinase gene, ALK, to a 
nucleolar protein gene, NPM, in non-Hodgkin's lymphoma. Science 1994;263:1281-4.

11. Wellmann A, Otsuki T, Vogelbruch M, Clark HM, Jaffe ES, Raffeld M. Analysis of the $\mathrm{t}(2 ; 5)(\mathrm{p} 23 ; \mathrm{q} 35)$ translocation by reverse transcription-polymerase chain reaction in CD30+ anaplastic large-cell lymphomas, in other non-Hodgkin's lymphomas of T-cell phenotype, and in Hodgkin's disease. Blood 1995;86:2321-8.

12. Shiota M, Nakamura S, Ichinohasama R, Abe M, Akagi T, Takeshita M, et al. Anaplastic large cell lymphomas expressing the novel chimeric protein p80 NPM/ALK: a distinct clinicopathologic entity. Blood 1995;86:1954-60.

13. Fujimoto J, Shiota M, Iwahara T, Seki N, Satoh H, Mori S, et al. Characterization of the transforming activity of $\mathrm{p} 80$, a hyperphosphorylated protein in a Ki-1 lymphoma cell line with chromosomal translocation t(2;5). Proc Natl Acad Sci U S A 1996;93:4181-6.

14. Chang Y, Cesarman E, Pessin MS, Lee F, Culpepper J, Knowles DM, et al. Identification of herpesvirus-like DNA sequences in AIDS-associated Kaposi's sarcoma. Science 1994;266:1865-9.

15. Cesarman E, Chang Y, Moore PS, Said JW, Knowles DM. Kaposi's sarcoma-associated herpesvirus-like DNA sequences in AIDS-related body-cavity-based lymphomas. N Engl J Med 1995;332:1186-91.

16. Nador RG, Cesarman E, Chadburn A, Dawson DB, Ansari MQ, Sald J, et al. Primary effusion lymphoma: a distinct clinicopathologic entity associated with the Kaposi's sarcoma-associated herpes virus. Blood 1996;88:645-56.

17. Soulier J, Grollet L, Oksenhendler E, Cacoub P, Cazals HD, Babinet $\mathrm{P}$, et al. Kaposi's sarcoma-associated herpesviruslike DNA sequences in multicentric Castleman's disease. Blood 1995;86:1276-80.

18. Gaidano G, Pastore C, Gloghini A, Cusini M, Nomdedeu J, Volpe G, et al. Distribution of human herpesvirus-8 sequences throughout the spectrum of AIDS-related neoplasia. AIDS 1996;10:941-9.

19. Renne R, Lagunoff M, Zhong W, Ganem D. The size and conformation of Kaposi's sarcoma-associated herpesvirus (human herpesvirus 8) DNA in infected cells and virions. J Virol 1996;70:8151-4.

20. Russo JJ, Bohenzky RA, Chien MC, Chen J, Yan M, Maddalena D, et al. Nucleotide sequence of the Kaposi sarcoma- associated herpesvirus (HHV8). Proc Natl Acad Sci U S A 1996;93:14862-7.

21. Bais C, Santomasso B, Coso O, Arvanitakis L, Raaka EG, Gutkind JS, et al. G-protein-coupled receptor of Kaposi's sarcoma-associated herpesvirus is a viral oncogene and angiogenesis activator. Nature 1998;391:86-9.

22. Gao SJ, Boshoff C, Jayachandra S, Weiss RA, Chang Y, Moore PS. KSHV ORF K9 (vIRF) is an oncogene which inhibits the interferon signaling pathway. Oncogene 1997;15:1979-85.

23. Nakamura K, Katano H, Hoshino Y, Nakamura T, Hosono O, Masunaga A, et al. Human herpesvirus type 8 (HHV-8) and Epstein-Barr virus (EBV)-associated cutaneous lymphoma taking anaplastic large cell morphology in an HIV-positive patient. Br J Dermatol 1999;141:141-5.

24. Katano H, Hoshino Y, Morishita Y, Nakamura T, Satoh H, Iwamoto A, et al. Establishing and characterizing a CD30positive cell line harboring HHV-8 from primary effusion lymphoma. J Med Virol 1999;58:394-401.

25. Katano H, Satoh Y, Kurata T, Mori S, Sata T. High expression of HHV-8-encoded ORF73 protein in spindle-shaped cells of Kaposi's sarcoma. Am J Pathol 1999;155:47-52.

26. Hsu SM, Raine L, Fanger H. Use of avidin-biotin-peroxidase complex $(\mathrm{ABC})$ in immunoperoxidase techniques: a comparison between $\mathrm{ABC}$ and unlabeled antibody (PAP) procedures. J Histochem Cytochem 1981;29:577-80.

27. Zhong W, Wang H, Herndier B, Ganem D. Restricted expression of Kaposi sarcoma-associated herpesvirus (human herpesvirus 8) genes in Kaposi sarcoma. Proc Natl Acad Sci U S A 1996;93:6641-6.

28. Glickman JN, Howe JG, Steitz JA. Structural analyses of EBER1 and EBER2 ribonucleoprotein particles present in Epstein-Barr virus-infected cells. J Virol 1988;62:902-11.

29. Kinney MC, Collins RD, Greer JP, Whitlock JA, Sioutos N, Kadin ME. A small-cell-predominant variant of primary Ki-1 (CD30) + T-cell lymphoma. Am J Surg Pathol 1993;17:859-68.

30. Lukes RJ, Collins RD, editors. Atlas of tumor pathology: tumors of the hematopoietic system. 2nd ed. Washington, DC: Armed Forces Institute of Pathology; 1992.

31. Burger R, Neipel F, Fleckenstein B, Savino R, Ciliberto G, Kalden JR, et al. Human herpesvirus type 8 interleukin-6 homologue is functionally active on human myeloma cells. Blood 1998;91:1858-63. 